Agricultural Journal 14 (4): 66-69, 2019

ISSN: 1816-9155

(C) Medwell Journals, 2019

\title{
Genetic Variability and Factor Analysis in Rapeseed (Brassica Rapa L.) Germplasm Collection for Yield Related Traits
}

\author{
${ }^{1}$ Asmat Ara, ${ }^{1}$ P.A. Sofi, ${ }^{2}$ Z. A. Dar, ${ }^{1}$ M.A.Rather, ${ }^{1}$ Munezeh Rashid and ${ }^{1}$ Musharib Gull \\ ${ }^{1}$ Division of Genetics and Plant Breeding, Wadura, 193201 Sopore, India \\ ${ }^{2}$ Dryland Agriculture Research Station, Budgam, India
}

\begin{abstract}
The Principal Component Analysis (PCA), one of multivariate analysis methods elucidates among a set of the traits which ones are decisive in genotypic differentiation and selection. The present study was undertaken in rabi 2013-14 at three locations. The collection comprising of 10 genotypes including two checks namely SS-1 and farmer's variety was studied using factor analysis. Ten quantitative traits related to seed yield namely days to flowering, days to maturity, plant height, primary branches plant ${ }^{-1}$, length of main raceme $(\mathrm{cm})$, number of siliquae on main raceme, number of siliqua/plant, number of seeds siliqua ${ }^{-1}, 1000$-seed weight and seed yield/plant. Analysis of variance revealed that there were significant differences between checks and accessions between accessions and between checks for all the traits. It indicated presence of substantial amount of variation among the test entries. The factor analysis was based on Pearson correlation matrix and euclidean distances. Total variance explained by the first principal component was $67.03 \%$ and the variation explained by the second component with $10.6 \%$. Latent roots (eigen values) are between 6.703 for the first and 1.06 for the second. Plant height and 1000-seed weight were the important traits in the first principal component. Primary branches per plant and number of siliqua on main raceme were the important traits in second principal component.
\end{abstract}

Key words: Genotype; principal component, trait, variation, eigen values, euclidean distances

\section{INTRODUCTION}

Brassica rapa L. commonly known as field mustard or turnip mustard belonging to the family Brassicaceae. The seeds of Brassica rapa L. contain $42 \%$ oil and $25 \%$ protein. It also serves as important source of raw material for industrial use such as in making soaps, paints, hair oils, lubricants, textile auxiliaries, pharmaceuticals and so, on. It is the third most important oil crop in the world accounting for over $16 \%$ of the world's edible oil supply. India holds a premier position in rapeseed-mustard economy of the world with 2nd and 3rd rank in area and production, respectively. It is the third largest rapeseedmustard producer in the world after China and Canada with $12 \%$ of world's total production (Gupta and Pratap, 2007). It is grown on an area of $5.8 \mathrm{~m}$ ha with a production of $6.8 \mathrm{mt}$ and an average productivity of $1.17 \mathrm{t} \mathrm{ha}^{-1}$ (Anonymous, 2013). This crop accounts for nearly one third of the oil produced in India, making it the country's key edible oilseed crop after groundnut and soybean. This group of oilseed crops is gaining wide acceptance because of adaptibility for both rainfed as well as irrigated areas and suitability for sole as well as mixed cropping. Being a major rabi (winter season) oilseed crop it has greater potential to increase the availability of edible oil from the domestic production. Despite its wide adaptability for varied agro-climatic conditions, the area, production and yield of rapeseed-mustard in India have been fluctuating due to various biotic and abiotic stresses coupled with India's domestic price support programmes. Nevertheless, the crop has a potential to ensure the nutritional security and contribute to livelihood security as well.

In the state of Jammu and Kashmir, brown sarson is the major oilseed crop cultivated on a large scale. During the year 2012-13, the crop was grown on an area of 0.67 lakh ha with a production of 5.32 lakh quintals and an average productivity of 7.94 quintals ha $^{-1}$ (Anonymous, 2013). Not much work has been carried out on genetic improvement of brown sarson. In order to achieve higher production and consequently change the edible oilseed scenario of the state it is imperative to develop improved varieties with high yielding ability, high oil content and early maturity. Besides yield potential, the variety should also possess stability in its performance over a range of environments. Knowledge on the interaction and stability is foremost in breeding varieties for wider adaptation in adverse agro-climatic conditions. The aim of the breeding programme should be to develop genotypes that can withstand unpredictable transient environmental fluctuations.

Corresponding Author: Asmat Ara, Division of Genetics and Plant Breeding, Wadura, 193201 Sopore, India 
Agric. J., 14 (4): 66-69, 2019

In order to increase the existing genetic variability and to develop rapeseed cultivars that will have high seed and oil yield potential, exploitation of the gene pool is of foremost importance. Many researchers have been evaluating the diversity in different collections of rapeseed genotypes using multivariate techniques (Choudhary and Joshi, 2001). Existence of genetic diversity is very essential to meet the present and future crop breeding challenges. It is a prerequisite for the development of improved cultivars with wider adaptability and broad genetic base. It can be estimated through biometrical procedures such as mahalanobis's D2-statistic and is possible to choose genetically diverse parents. Diversity analysis greatly helps the breeder in identification and proper choice of parents for specific breeding objectives. The selection of potential varieties in a breeding program is based on the knowledge of genetic diversity amongst them. Therefore the present study was undertaken to collect information on genetic divergence in the genotypes and selection of suitable diverse parents for the utilization in future hybridization program.

The Principal Component Analysis (PCA), one of multivariate analysis methods elucidates among a set of the traits which ones are decisive in genotypic differentiation. PCA enables easier understanding of impacts and connections among different traits by identifying them and explaining their roles. This method is a powerful multiple method to apply evaluation yield component, identify biological relationships among traits (Acquaah et al., 1992) decrease associated-traits to a few factors (Johnson and Wichern, 1996) and description of correlations among variables. Factor analysis has the potential of enhancing our knowledge of causal relationship of variables and can help to know the nature and sequences of traits to be selected for breeding program (Khameneh et al., 2012).

\section{MATERIAL AND METHODS}

The present study was undertaken in rabi 2013-14. The basic material for the study comprised 10 genotypes of brown sarson (Brassica rapa L.). Each genotype was grown in a 3-row experimental plot of $3 \mathrm{~m}$ length with inter and intra row spacing of 30 and $10 \mathrm{~cm}$, respectively. The plants were space planted for optimal expression of traits and lack of prior knowledge about growth habit of the genotypes. Data was collected from five randomly selected competitive plants on various morphological, maturity, yield and yield contributing traits. The analysis of variance was done using WINDOSTAT advanced biometrics software. We considered ten quantitative traits related to seed yield namely days to flowering, days to maturity, plant height, primary branches plant ${ }^{-1}$, length of main raceme $(\mathrm{cm})$, number of siliquae on main raceme, number of siliqua/plant, number of seeds siliqua ${ }^{-1}$, 1000-seed weight and seed yield/plant. The factor analysis was based on Pearson correlation matrix and Euclidean distances. Latent roots or eigen values for all principal components were shown. The variability of the collection in was interpreted based on the seven principal components. Non-rotated and rotated values of latent vectors (component weights, factor loadings) were shown. The Varimax method was used for the rotation of principal components. Both the unrotated and the varimex rotated PCA values were calculated by the statistical package StatistiXL.

\section{RESULTS AND DISCUSSION}

Principal Component Analysis (PCA): PCA is a statistical method which attempts to describe the total variation in multivariate sample using fewer variables than in the original data set. In the end, the analysis results in the identification of the major attributes that are responsible for the observed variation within a given collection. Principal component analysis was carried out with 10 genotypes of Brassica rapa L. (Table 1). The computed eigen values for the 9 variables subjected to principal component analysis, together with the corresponding proportion and cumulative explained variances are given in Table 2. The first principal component accounted for $64.57 \%$ of the total variation while principal components two and three accounted for 9.22 and $4.30 \%$, respectively. The fourth principal component accounted for $2.43 \%$ and 1.020 variability.

Table 1: Mean performance for 10 rapeseed genotypes for 10 quantitative traits

\begin{tabular}{|c|c|c|c|c|c|c|c|c|c|c|}
\hline Genotypes & $\overline{D F}$ & DM & $\mathrm{PH}$ & PBPP & LMR & NSMR & NSPP & NSPS & 100SW & SYPP \\
\hline KBS-69 & 170.1 & 222.8 & 122.2 & 6.1 & 0.01 & 57.65 & 220.7 & 18.66 & 3.13 & 6.34 \\
\hline KBS-33 & 168.4 & 222.6 & 122.8 & 6.64 & 0.006 & 55.73 & 220.1 & 19.18 & 3.12 & 6.15 \\
\hline KBS-49 & 167.6 & 221.7 & 126.2 & 6.89 & 0.016 & 57.67 & 229.6 & 20.02 & 3.19 & 6.68 \\
\hline KBS-38 & 170.2 & 222.8 & 124.2 & 6.61 & 0.01 & 56.76 & 225.9 & 16.11 & 3.17 & 6.53 \\
\hline KBS-5 & 168.8 & 224.8 & 119.8 & 6.32 & 0.012 & 49.79 & 214.8 & 18.85 & 3.11 & 5.64 \\
\hline KBS-40 & 171 & 223.9 & 114.3 & 6.11 & 0.019 & 49.06 & 210.4 & 16.27 & 2.89 & 5.41 \\
\hline FV & 171.6 & 225.1 & 110.8 & 5.88 & 0.02 & 48.39 & 209.2 & 14.78 & 2.7 & 4.32 \\
\hline KBS-28 & 171.1 & 225.7 & 118 & 6.4 & 0.02 & 53.2 & 215.1 & 17.74 & 3.08 & 5.12 \\
\hline KS-101 & 170.1 & 223.4 & 113.5 & 5.51 & 0.017 & 54.36 & 209.6 & 17.06 & 3.01 & 3.67 \\
\hline SS-1 & 170.6 & 224.3 & 120.5 & 5.42 & 0.018 & 55.39 & 219.1 & 17.53 & 2.99 & 3.52 \\
\hline Mean & 169.95 & 223.71 & 119.23 & 6.188 & 0.0148 & 53.8 & 217.45 & 17.62 & 3.039 & 5.338 \\
\hline
\end{tabular}


Agric. J., 14 (4): 66-69, 2019
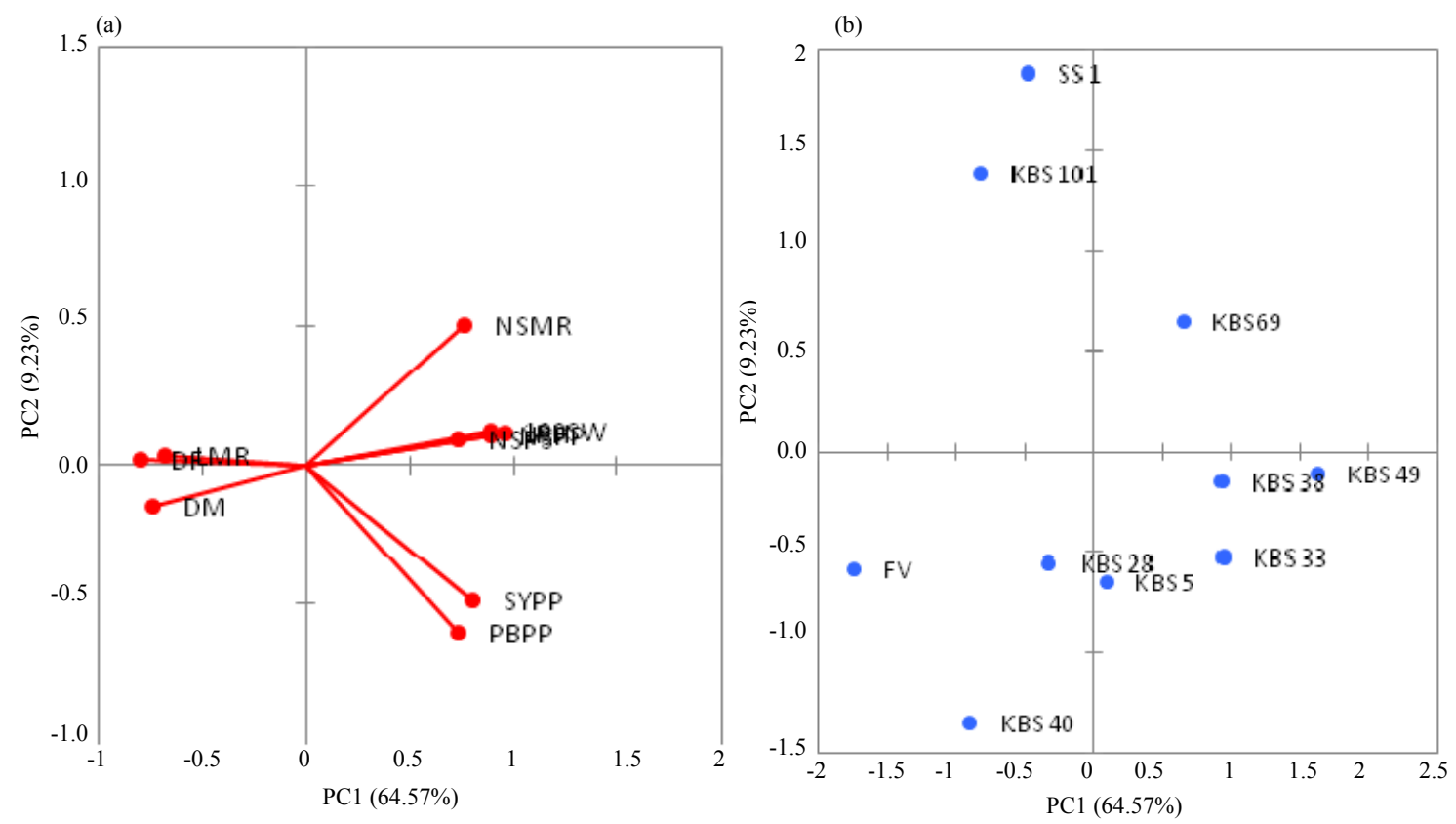

Fig. 1(a-b): Genotype v/s trait biplot for yield traits (a) Factor loadings (axes F1 and F2: $73.80 \%$ ) and (b) Observations (axes F1 and F2: $73.80 \%$ )

Table 2: Eigen values (Latent roots) and rotated component loadings (values of principal component traits of rapeseed)

\begin{tabular}{lccc}
\hline $\begin{array}{l}\text { Principal } \\
\text { component }\end{array}$ & $\begin{array}{l}\text { Eigen } \\
\text { value }\end{array}$ & Variability (\%) & $\begin{array}{l}\text { Cumulative } \\
\text { variability (\%) }\end{array}$ \\
\hline PC 1 & 6.457 & 64.571 & 64.571 \\
PC 2 & 0.923 & 9.228 & 73.800 \\
PC 3 & 0.430 & 4.305 & 78.104 \\
PC 4 & 0.243 & 2.432 & 80.536 \\
PC 5 & 0.102 & 1.020 & 81.557 \\
\hline
\end{tabular}

Table 3: Factors loadings for component character traits in principal component 1-5

\begin{tabular}{lrrrrr}
\hline Trait & PC 1 & PC 2 & PC 3 & PC 4 & PC 5 \\
\hline DF & -0.315 & 0.020 & 0.540 & -0.206 & 0.345 \\
DM & -0.290 & -0.154 & -0.142 & -0.589 & 0.322 \\
PH & 0.376 & 0.115 & 0.105 & -0.371 & 0.079 \\
PBPP & 0.290 & -0.625 & 0.089 & -0.229 & -0.264 \\
LMR & -0.268 & 0.035 & 0.054 & -0.451 & -0.472 \\
NSMR & 0.303 & 0.525 & 0.343 & 0.035 & 0.016 \\
NSPP & 0.349 & 0.109 & 0.352 & -0.256 & -0.362 \\
NSPS & 0.291 & 0.096 & -0.569 & -0.139 & -0.079 \\
100SW & 0.349 & 0.126 & -0.186 & -0.289 & 0.513 \\
SYPP & 0.315 & -0.508 & 0.259 & 0.219 & 0.278 \\
\hline
\end{tabular}

Contribution of characters towards divergence of the genotypes: The factor loadings of characters from PCA retained five components identified the major characters responsible for maximum variability Table 3 . The largest contribution to PC1 was by plant height (0.376) followed by 100 -seed weight and number of siliqua per plant. Maximum contribution to PC2 was by number of siliqua on main raceme followed by 100 -seed weight $(0.126)$ and plant height (0.115). The largest contribution to PC3 was by days to flowering $(0.540)$ followed by number of siliqua per plant (0.352) and number of siliqua on main raceme (0.343). For PC4, number of siliqua on main raceme (0.035) contributed the most and days to maturity $(-0.589)$ contributed the least. Days to flowering $(0.345)$ contributed the most to PC5 and length of main raceme (-0.472) the least (Fig. 1).

\section{CONCLUSION}

The principal component analysis was effective for classification of the quantitative traits that explained most of the variability of the studied genotypes. In this data set, the characters were appointed to five PCs, out of which the first three PCs explained $63 \%$ of the total variance. It served as a useful tool for detection of traits for which the genotypes expressed the highest differences and facilitated the choice of variables based on which the clustering of the germplasm could be performed.

\section{REFERENCES}

Acquaah, G., M.W. Adams and J.D. Kelly, 1992. A factor analysis of plant variables associated with architecture and seed size in dry bean. Euphytica, 60: $171-177$.

Anonymous, 2013. Area and productivity of oilseed in J\&K State. Digest of Statistics, Directorate of Economics and Statistics Planning and Development Department, Jammu and Kashmir.

Choudhary, B.R. and P. Joshi, 2001. Genetic diversity in advanced derivatives of Brassica interspecific hybrids. Euphytica, 121: 1-7. 
Gupta, S.K. and A. Pratap, 2007. History, origin and evolution. Adv. Bot. Res., 45: 1-20.

Johnson, R.A. and D.W. Wichern, 1996. Applied Multivariate Statistical Analysis. Sterling Book House, Mumbai, India,.
Khameneh, M.M., S. Bahraminejad, F. Sadeghi, S.J. Honarmand and M. Maniee, 2012. Path analysis and multivariate factorial analyses for determining interrelationships between grain yield and related characters in maize hybrids. Afr. J. Agric. Res., 7: 6437-6446. 